\title{
Heart Mitochondrial Metabolic Flexibility and Redox Status Are Improved by Donkey and Human Milk Intake
}

\author{
Giovanna Trinchese ${ }^{1,2} \mathbb{D}$, Fabiano Cimmino ${ }^{1}$, Gina Cavaliere ${ }^{1}$, Luigi Rosati ${ }^{1,2} \mathbb{D}$, Angela Catapano ${ }^{1,3}$, \\ Daniela Sorriento ${ }^{4}$, Elisabetta Murru ${ }^{5}$, Luca Bernardo ${ }^{6}$, Luciana Pagani ${ }^{6}$, Paolo Bergamo ${ }^{7}$ (D), \\ Rosaria Scudiero ${ }^{1,2} \mathbb{D}$, Guido Iaccarino ${ }^{4}\left(\mathbb{D}\right.$, Luigi Greco ${ }^{8}$, Sebastiano Banni ${ }^{5}$, Marianna Crispino ${ }^{1}$ (D) \\ and Maria Pina Mollica 1,2,9,*
}

\section{check for} updates

Citation: Trinchese, G.; Cimmino, F.; Cavaliere, G.; Rosati, L.; Catapano, A.; Sorriento, D.; Murru, E.; Bernardo, L.; Pagani, L.; Bergamo, P.; et al. Heart Mitochondrial Metabolic Flexibility and Redox Status Are Improved by Donkey and Human Milk Intake. Antioxidants 2021, 10, 1807. https:// doi.org/10.3390/antiox10111807

Academic Editors: Ashley J. Smuder and Francesca Giampieri

Received: 15 October 2021

Accepted: 11 November 2021

Published: 13 November 2021

Publisher's Note: MDPI stays neutral with regard to jurisdictional claims in published maps and institutional affiliations.

Copyright: (c) 2021 by the authors. Licensee MDPI, Basel, Switzerland. This article is an open access article distributed under the terms and conditions of the Creative Commons Attribution (CC BY) license (https:/ / creativecommons.org/licenses/by/ $4.0 /)$.
1 Department of Biology, University of Naples Federico II, 80126 Naples, Italy; giovanna.trinchese@unina.it (G.T.); fabiano.cimmino@unina.it (F.C.); gina.cavaliere@unina.it (G.C.); luigi.rosati@unina.it (L.R.); angela.catapano@me.com (A.C.); rosaria.scudiero@unina.it (R.S.); crispino@unina.it (M.C.)

2 BAT Centre-Interuniversity Centre for Studies on Bioinspired Agro-Environmental Technology, University of Naples Federico II, 80055 Naples, Italy

3 Department of Pharmacy, University of Naples Federico II, 80131 Naples, Italy

4 Department of Advanced Biomedical Sciences, University of Naples Federico II, 80131 Naples, Italy; danisor@libero.it (D.S.); guido.iaccarino@unina.it (G.I.)

5 Department of Biomedical Sciences, University of Cagliari, 09042 Cagliari, Italy; m.elisabetta.murru@gmail.com (E.M.); banni@unica.it (S.B.)

6 Department of Childhood and Developmental Medicine, ASST Fatebenefratelli-Sacco, 20157 Milan, Italy; luca.bernardo@fbf.milano.it (L.B.); lucianapagani@gmail.com (L.P.)

7 Institute of Bioscience and Bioresources CNR, IBBR-UOS, 80131 Naples, Italy; paolo.bergamo@ibbr.cnr.it

8 Department of Translational Medical Sciences, Section of Pediatrics, University of Naples Federico II, 80131 Naples, Italy; luigi.greco@unina.it

9 Task Force on Microbiome Studies, University of Naples Federico II, 80100 Naples, Italy

* Correspondence: mariapia.mollica@unina.it; Tel.: +39-081-679-990

\begin{abstract}
The biological mechanisms linking nutrition and antioxidants content of the diet with cardiovascular protection are subject of intense investigation. It has been demonstrated that dietary supplementation with cow, donkey or human milk, characterized by distinct nutritional properties, triggers significant differences in the metabolic and inflammatory status through the modulation of hepatic and skeletal muscle mitochondrial functions. Cardiac mitochondria play a key role for energydemanding heart functions, and their disfunctions is leading to pathologies. Indeed, an altered heart mitochondrial function and the consequent increased reactive oxygen species (ROS) production and inflammatory state, is linked to several cardiac diseases such as hypertension and heart failure. In this work it was investigated the impact of the milk consumption on heart mitochondrial functions, inflammation and oxidative stress. In addition, it was underlined the crosstalk between mitochondrial metabolic flexibility, lipid storage and redox status as control mechanisms for the maintenance of cardiovascular health.
\end{abstract}

Keywords: heart mitochondria; oxidative stress; nutrition; milk; antioxidants; fatty acids

\section{Introduction}

Human health depends on the maintenance of metabolic homeostasis to prevent the onset of chronic low-grade inflammation that causes later chronic disease, such as obesity and its comorbidities, some cancers and cardiovascular diseases (CVD) [1]. To maintain metabolic homeostasis the organism developed a "metabolic flexibility", i.e., the capacity to efficiently adapt fuel oxidation to nutrients availability, managing sensing, uptake, trafficking, storage and expenditure of the nutrients [2]. The mitochondria, the most important players in the management of metabolic flexibility, adjust the capacity and efficiency of adenosine triphosphate (ATP) generation in response to energetic demands 
to keep the organism healthy [3]. Accordingly, mitochondrial dysfunction is linked to the development of metabolic pathologies [4].

The heart, along with the liver and skeletal muscle, is one of the metabolically very active organs since it needs intense energy production to generate the contractile force. It has been known for several decades that cellular ATP production plays a key role in heart function [5-10]. Accordingly, the expression of ATP synthase is linked to the function of the myocardium [11-14]. Cardiac mitochondria, beyond the regulation of energy metabolism, are known to regulate other essential cardiomyocyte functions like contractility, reactive oxygen species (ROS) production, apoptosis, as well as differentiation and development [15-17]. In addition, the evidence showing the contribution of cardiac mitochondria to the onset of several heart diseases, suggests their key role in the heart physiopathology [17-19]. Therefore, it is intriguing to hypothesize a nutritional intervention during early postnatal life to prevent CVD, acting on metabolic, microbiological and immunological development $[20,21]$. From this point of view, breastfeeding may have protective effects on CVD risk factor profiles in adulthood [22,23], leading to small reductions in adolescent and adult blood pressure levels [24-26], decreased total cholesterol and low-density lipoprotein (LDL) cholesterol levels in adulthood $[25,27,28]$ and modest decrease in adult body mass index [29]. Nutritional intervention may imply the modulation of mitochondrial metabolism since it has been already demonstrated that acting on mitochondrial metabolism in high-metabolic-rate organs (i.e., liver and skeletal muscle), is an effective preventive strategy to relieve the burden of non-communicable diseases [30-33]. Nonetheless, the biological mechanisms underlying the modulatory activity of nutrition on the cardiovascular long-term protection are still far from being completely understood.

Recently, the attention of nutrition research switches from individual nutrients to a complete dietary pattern [34]. Accordingly, dietary recommendations specifically identified low-fat and fat-free dairy foods as components of healthy eating patterns.

Milk is undoubtedly an omnipresent food in the human diet: not only it is a gold standard food for infant nutrition, but humans keep drinking milk after weaning reinforcing its role as an important macro and micronutrients source.

The main concern related to a possible influence of milk consumption on heart disease is related to the quality of its fat content, micronutrients components and, consequently, antioxidant properties $[35,36]$. The different physicochemical and nutritional properties among cow (CM), donkey (DM) or human (HM) milk may be responsible for their significant differences in the regulation of energy balance, glucose and lipid metabolism, inflammatory and redox state attributable to the modulation of hepatic and muscular mitochondrial function $[37,38]$. This evidence suggests that the potential influence of milk consumption in the regulation of cardiovascular health could be sought in the multiplicities of cardiac mitochondrial functions which extend beyond energy provision, such as ROS production and regulation of inflammatory responses. Therefore, in this study we investigate the effects of supplementation of rat diet with CM, DM and HM on heart mitochondrial functions, inflammation and redox homeostasis.

\section{Materials and Methods}

\subsection{Materials Used}

All chemicals were purchased from Sigma-Aldrich (St. Louis, MO, USA), unless specified otherwise. Cow milk (CM) was obtained from the "Nuova Latte Soc. Coop. Agr. A R.L." (Contrada Isca SNC, Eboli, SA, Italy). Donkey milk (from the Ragusana breed) (DM) was obtained from the "Az. Agric. Garofalo Patrizia" (Contrada Valle Cerasa, Casalbordino, $\mathrm{CH}$, Italy). Human milk (HM) was kindly provided by the milk bank of the Macedonio Melloni Hospital (Department of Childhood and Evolutionary Age Medicine, Milano, Italy). Standard rodent diet (4RF21) was purchased from Mucedola (Mucedola srl, Settimo Milanese, MI, Italy). 


\subsection{Animal Treatment and Energy Balance Assessment}

Male Wistar rats (60 days old; $345 \pm 7$ g; Charles River, Calco, Lecco, Italy) were individually caged in a temperature-controlled room and exposed to a daily light-dark cycle $(12 / 12 \mathrm{~h})$ with free access to standard rodent diet $(15.88 \mathrm{~kJ} / \mathrm{g})$ and drinking water. The rats were divided into four experimental groups $(n=7)$. Three of them received a 4-weeks supplementation with equicaloric intake ( $82 \mathrm{~kJ}$ ) of raw CM, DM or HM drinking 21,48 or $22 \mathrm{~mL} /$ day respectively, according to the experimental plan previously reported [37,38]. The last group did not receive milk supplement and was used as control. Despite the different volumes used, the energy density provided by the different milk supplements was kept the same. During the treatments, the body weights and food intake were monitored daily to calculate weight gain and gross energy intake. Spilled food and feces were collected daily for precise food intake and metabolizable energy intake calculation.

At the end of the treatments, the animals were anesthetized by intraperitoneal injection of chloral hydrate ( $40 \mathrm{mg} / 100 \mathrm{~g}$ body weight), and blood was taken from the inferior cava. Hearts were removed, parts of the hearts were washed in calcium-free PBS to remove blood residues, fixed for $24 \mathrm{~h}$ in $4 \%$ buffered paraformaldehyde, $\mathrm{pH} 7.4$ and then embedded in paraffin. Other aliquots not immediately used for mitochondrial preparation and for histological analyses were stored at $-80^{\circ} \mathrm{C}$. All experiments were conducted in compliance with national guidelines for the care and use of research animals and were approved by the institutional committee (Comitato Etico-Scientifico per la Sperimentazione Animale of the University of Naples Federico II) and authorized by the Italian Ministry of Health (Ethical approval number: 97/2019-PR).

Energy balance assessments were conducted over the 4 weeks of treatment by the comparative carcass evaluation [39]. Metabolizable energy intake was obtained by subtracting the energy measured in the feces and urine from the gross energy intake, which was determined from the daily food consumption and gross energy density. The gross energy density for the standard diet, CM, DM or HM $(15.8,14.04,13.79$ or $14.01 \mathrm{~kJ} / \mathrm{g}$, respectively) as well as the energy density of the feces and the carcasses were determined by bomb calorimeter (Parr adiabatic calorimeter, Parr Instrument Co., Moline, IL, USA). The evaluation of the energy, fat and protein content in animal carcasses was conducted according to a previously published protocol $[39,40]$.

\subsection{Evaluation of Inflammatory Markers}

Commercially available ELISA kits were used to determine interleukin- $1 \alpha$ (IL- $1 \alpha)$, interleukin-10 (IL-10) and tumor necrosis factor-alpha (TNF- $\alpha$ ) (Thermo Scientific, Rockford, IL; Biovendor R and D, Brno, Czech Republic) concentrations in serum and inheart homogenates.

\subsection{Heart Lipid Content Measurement}

Total lipids were extracted by the method of Folch et al. [41]. Total lipid quantification was performed by the method of Chiang et al. [42]. Aliquots of total lipid extract from heart were mildly saponified as previously described [43] in order to obtain free fatty acids. Separation of unsaturated fatty acids was carried out with an Agilent 1100 HPLC system (Agilent, Palo Alto, CA, USA) equipped with a diode array detector [44]. Saturated fatty acids were measured as fatty acid methyl esters, by a gas chromatograph (Agilent, Model 6890, Palo Alto, CA, USA) equipped with a flame ionization detector; the split ratio was set at 20:1 and the injection port temperature was $270{ }^{\circ} \mathrm{C}$ and a $100 \mathrm{~m} \mathrm{HP}-88$ fused capillary column (Agilent, Palo Alto, CA, USA) were used. Data were acquired by the Agilent OpenLab ChemStation software system (CDS 2.4, Agilent Technologies, Santa Clara, CA, USA).

Quantification of endocannabinoidome was conducted by an Agilent 1100 HPLC system equipped with a mass spectrometry Agilent Technologies QQQ triple quadrupole 6420 with electrospray ionization source (Agilent Technologies, Santa Clara, CA, USA), using positive mode (ESI+) and using as internal standards their deuterated homologs as 
previously described [45]. Data were acquired by the MassHunter workstation acquisition software (version B.08.02, Agilent Technologies, Santa Clara, CA, USA), analyzed with MassHunter software for qualitative (version B.08.00 SP1 Agilent Technologies, Santa Clara, CA, USA) and quantitative analyses (version B.09.00, Agilent Technologies, Santa Clara, CA, USA). Endocannabinoidome compounds were expressed as $\mathrm{pmol} / \mathrm{g}$ tissue.

\subsection{Mitochondrial Isolation Procedure}

The hearts were finely minced and washed in a medium containing $100 \mathrm{mmol} / \mathrm{LKCl}$, $50 \mathrm{mmol} / \mathrm{L}$ Tris, $\mathrm{pH} 7.5,5 \mathrm{mmol} / \mathrm{L} \mathrm{MgCl} 2,1 \mathrm{mmol} / \mathrm{L}$ ethylenediamine tetraacetic acid (EDTA), $5 \mathrm{mmol} / \mathrm{L}$ ethylene glycol tetraacetic acid (EGTA), $1 \mathrm{~g} / \mathrm{L}$ fatty acid-free bovine serum albumin (BSA). Tissue fragments were treated with protease nagarse (E.C. 3.4.21.62; $1 \mathrm{mg} / \mathrm{g}$ tissue) for $5 \mathrm{~min}$, washed, homogenized for $1 \mathrm{~min}$ with the above medium (1:8, $w / v)$ in a Potter Elvehjem homogenizer (Heidolph, Kelheim, Germany) set at $500 \mathrm{rpm}$ (4 strokes/min) and filtered. The homogenate was centrifuged at $3000 \times g$ for $10 \mathrm{~min}$, the pellet containing unbroken cells, nuclei, as well as mitochondria, was washed twice, resuspended in a suspension medium containing $250 \mathrm{mmol} / \mathrm{L}$ sucrose, $50 \mathrm{mmol} / \mathrm{L}$ Tris, $\mathrm{pH} 7.5,1 \mathrm{~g} / \mathrm{L}$ fatty acid-free BSA and centrifuged at $700 \times \mathrm{g}$ for $10 \mathrm{~min}$. The resulting supernatant fraction was again centrifuged at $3000 \times g$ for $10 \mathrm{~min}$. The mitochondrial pellet was washed twice and finally re-suspended in the suspension medium. The protein content of the mitochondrial suspension was determined by the method of Hartree [46] using BSA as the protein standard. Isolated mitochondria were then used for the determination of respiratory parameters.

\subsection{Measurement of Mitochondrial Oxygen Consumption}

Mitochondrial oxygen consumption was polarographically measured by a Clark-type electrode (Yellow Springs Instruments, Yellow Springs, $\mathrm{OH}, \mathrm{USA}$ ) at $30^{\circ} \mathrm{C}$. In detail, isolated mitochondria $(0.5 \mathrm{mg}$ protein $/ \mathrm{mL})$ were incubated in a medium containing $30 \mathrm{mM}$ $\mathrm{KCl}, 6 \mathrm{mM} \mathrm{MgCl}$, $75 \mathrm{mM}$ sucrose, $1 \mathrm{mM}$ EDTA, $20 \mathrm{mM} \mathrm{KH}_{2} \mathrm{PO}_{4} \mathrm{pH} 7.0$, and $0.1 \%(w / v)$ fatty acid-free BSA. State 3 oxygen consumption was measured in the presence of $10 \mathrm{mM}$ succinate $+3.75 \mathrm{mM}$ rotenone or of $2.5 \mathrm{mM}$ pyruvate $+5 \mathrm{mM}$ malate and after the addition of $0.6 \mathrm{mM}$ adenosine diphosphate (ADP). State 4 was obtained in the absence of ADP. The rate of mitochondrial fatty acid oxidation was assessed in the presence of $2.5 \mathrm{mM}$ malate + $40 \mu \mathrm{M}$ palmitoyl-L-carnitine and $0.6 \mathrm{mM}$ of ADP. The respiratory control ratio (RCR) was calculated as the ratio between states 3 and 4 . In control experiments, we assured the quality of our mitochondrial preparation by checking that contamination of mitochondria by other ATPase-containing membranes was lower than $10 \%$, and the addition of cytochrome $c$ $(3 \mathrm{nmol} / \mathrm{mg}$ protein) only enhanced state 3 respiratory rate by approximately $10 \%$.

\subsection{Evaluation of Redox Status}

The rate of mitochondrial hydrogen peroxide $\left(\mathrm{H}_{2} \mathrm{O}_{2}\right)$ release was assayed by following the linear increase in fluorescence (excitation 312, emission $420 \mathrm{~nm}$ ) due to the oxidation of homovanillic acid in the presence of horseradish peroxidase [47]. Superoxide dismutase (SOD) specific activity was measured spectrophotometrically $(550 \mathrm{~nm})$ at $25^{\circ} \mathrm{C}$, by monitoring the decrease in the reduction rate of cytochrome $\mathrm{c}$ by superoxide radicals, generated by the xanthine-xanthine oxidase system [48].

Catalase (CAT) activity was measured in heart homogenates, by monitoring the decrease in absorbance at $240 \mathrm{~nm}$ due to the decomposition of $\mathrm{H}_{2} \mathrm{O}_{2}$ [49].

To determine the lipid peroxidation in heart homogenate, the level of malondialdehyde (MDA) was measured using the thiobarbituric acid reaction (TBAR) method. MDA reacts with thiobarbituric acid (TBA) to form a pink chromogen that is detected at the wavelength of $532 \mathrm{~nm}$. MDA values were expressed as nanomoles per milligram of protein [50].

Reduced glutathione (GSH) and oxidized glutathione (GSSG) concentrations in the hearts of differently treated rats were measured with the dithionitrobenzoic acid-GSSG 
reductase recycling assay [51]. Upon normalization to the protein content, GSH and GSSG amount were finally expressed as nmoles $/ \mathrm{mg} \mathrm{prot} / \mathrm{min}$.

\subsection{Real-Time PCR}

Total RNA was extracted from $50 \mathrm{mg}$ of cardiac tissues ( $n=3$ /group) using a TRIzol reagent (Invitrogen, (ThermoFisher), Waltham, MA, USA), and cDNA was synthesized using the ThermoScript RT-PCR System (Invitrogen, (ThermoFisher), Waltham, MA, USA), following the manufacturer instruction. After reverse transcription reaction, real-time quantitative polymerase chain reaction (RT-PCR) was performed with the SYBR Green real-time PCR master mix kit (Applied Biosystems, Foster City, CA, USA) as described. The reaction was visualized by SYBR Green-derived fluorescence analysis on the StepOne instrument (Applied Biosystem, Applied Biosystem, (ThermoFisher) Waltham, MA, USA). All standards and samples were assayed in triplicate. All values obtained were normalized to the endogenous control $18 \mathrm{~S}$ using the formula $2^{-\Delta \mathrm{Ct}}$ and results are expressed as relative quantification (RQ). Primer sequences are shown in Table 1.

Table 1. Primer sequences for Real-Time PCR.

\begin{tabular}{|c|c|c|c|}
\hline Gene & Accession n ${ }^{\circ}$ (NCBI Database) & Sense Primer Sequence & Anti-Sense Primer Sequence \\
\hline $18 \mathrm{~S}$ & NR_003278 & 5'-GTAACCCGTTGAACCCCATT-3' & 5'CCATCCAATCGGTAGTAGCG-3' \\
\hline NDUFB 6 & NM_001033305.3 & 5'-ATAACTTTTTGCGGGACGGG-3' & 5'-CAGGAAAATCTCTCATTGGTG-3' \\
\hline SDHA & NM_023281.1 & 5'-CATACTGTTGCAGCAGCACAGG-3' & 5'-CCACCAAATGCACGCTGATA-3' \\
\hline ATPASE & NM_001302213.1 & 5'-TGTGGAAGGAAGTGGGCAA-3' & 5'-CCACTATGAGCTGGAGCCGT-3' \\
\hline $\operatorname{COX} 1$ & NP 904330.1 & 5'-GAAGAGACAGTGTTTCATGTGGTGT-3' & 5'-TCCTGGGCCTTTCAGGAATA-3' \\
\hline $\operatorname{COX} 4$ & NM_001293559.1 & 5'-GAGCACATGGGAGTGTTGTG-3' & 5'-CTGTCTTCCATTCATTGGTGCC-3' \\
\hline UQCRC I & NM̄_025407.2 & 5'-CCTACGCACTCGAGAGCAC-3' & 5'-AGGTGTGCCCTGGAATGCTG-3' \\
\hline UQCCRC II & NM_025899.2 & 5'-TCCCTCAAAGTTGCCCC-3' & 5'-GCAAGACGTAGTAAATGTGAG-3' \\
\hline $\begin{array}{c}\text { PGC1 } \\
\text { ALPHA }\end{array}$ & NM_008904.2 & 5'-AAACTTGCTAGCGGTCCTCA-3' & 5'-TGGCTGGTGCCAGTAAGAG-3' \\
\hline NRF1 & NM_001164226.1 & 5'-GCACCTTTGGAGAATGTGGT-3' & 5'-GGGTCATTTTGTCCACAGAGA-3' \\
\hline
\end{tabular}

18 S: 18 S Ribosomal RNA; NDUFB6: NADH-Ubiquinone Oxidoreductase Subunit B6; SDHA: succinate dehydrogenase complex flavoprotein subunit A; COX: cytochrome c oxidase 1 and 4; UQCRC: Ubiquinol-Cytochrome C Reductase Core Protein I and II; PGC-1 alpha: peroxisome proliferator-activated receptor gamma, coactivator 1 alpha; NRF1: nuclear respiratory factor 1.

\subsection{Light Microscopy}

Serial $6 \mu \mathrm{m}$ sections of the cardiac tissue embedded in paraffin were processed for routine histological analysis and stained with Mallory's trichromic stain, as previously described [52]. Briefly, the staining was carried out in two steps. In the first step, the sections were stained in $1 \%$ acid fucsin solution in distilled water; the second step involved counterstaining in a Mallory solution with $0.5 \%$ methyl blue, $2 \%$ orange $G$, and $2 \%$ oxalic acid in distilled water. Images were acquired with a camera connected to an IBM computer running the Kontron Elektronik KS 300 image analysis system (Carl Zeiss MicroImaging, Milan, Italy).

\subsection{Statistical Analyses}

All data were presented as means \pm SEM. Differences among groups were compared by one-way ANOVA followed by the Bonferroni post hoc test to correct for multiple comparisons. Fatty acids and endocannabinoidome data were not normally distributed; therefore, the differences between the groups were assessed using nonparametric Kruskal-Wallis test (one-way ANOVA on ranks) followed by Dunn's correction for multiple comparisons. Data were analyzed using GraphPad Prism 6.0 (GraphPad Software Inc., La Jolla, CA, USA) with $p \leq 0.05$ as the cut-off for statistical significance between groups. Data with different superscript letters were significantly different according to the statistical analysis, as specified in the figures and tables. 


\section{Results}

\subsection{Distinct Milk Administration Differently Modulates Body Weight Gain, Composition and Efficiency}

The effects produced in rats by diet supplementation of milk from three distinct animal species on energy balance and body composition are shown in Figure 1, confirming previous data [37]. Equicaloric administration of different milk provided similar metabolizable energy intake in all treated rats, significantly higher than controls $(p<0.001)$ (Figure 1A). Body weight gain, body energy and lipids percentage in CM group were significantly higher than in the control group $(p<0.001)$ (Figure 1B-D), while a decrease in body water was observed in CM-fed animals as compared to other groups $(p<0.001)$ (Figure 1E). Body protein content $(\%)$ was significantly increased by HM treatment $(p<0.001)$ (Figure $1 \mathrm{~F}$ ).
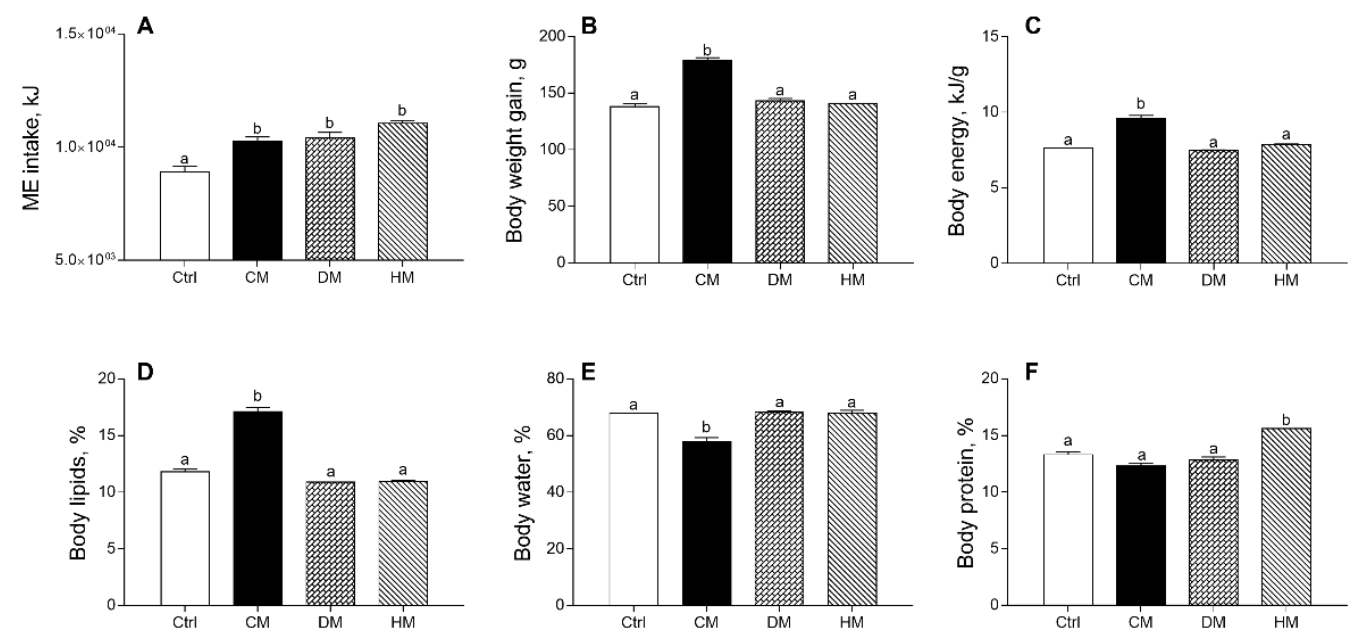

Figure 1. Cow milk (CM), donkey milk (DM) or human milk (HM) diet supplementation influences body weight gain and composition in rats. Metabolizable energy intake (ME) (A), body weight gain (B) during the study period (4 weeks), body energy (C), lipids (D), water (E) and protein (F) were reported. Data were expressed as the means $\pm \operatorname{SEM} n=7$ animals/group. Different letters $(a, b)$ on top of the bars indicate statistically significant differences $(p<0.05)$ among groups.

\subsection{Modulation of Serum and Tissue Inflammatory Profile in Rats Fed with Different Milk}

In rats fed with DM and HM, compared to other groups, the levels of proinflammatory markers (TNF- $\alpha$ and IL- $1 \alpha)$ were significantly reduced in both serum $(p<0.01)$ and cardiac tissue $(p<0.001)$ (Figure 2A,B). In addition, the levels of TNF- $\alpha$ in tissue of CM-treated rats were also higher than control animals $(p<0.05)$ (Figure 2A). Moreover, increased levels of the anti-inflammatory cytokine IL-10 were observed in DM- and HM-treated animals both in serum $(p<0.01)$ and in the heart $(p<0.001)$ (Figure $2 C)$. In cardiac tissue, no significant differences in total lipid content were observed in all treated groups (Figure 2D).

\subsection{Heart Mitochondrial Oxidative Capacity Is Modulated by the Administration of Milk from Different Animal Species}

Respiration rates of cardiac mitochondria were measured in the presence of succinaterotenone, palmitoyl carnitine-malate or pyruvate-malate as substrates. It is noteworthy that the stoichiometry of ATP synthesis to oxygen consumption is lower when lipids rather than carbohydrates are oxidized [53]. Regardless of the substrates used, state 3 and state 4 mitochondrial oxygen consumptions were significantly reduced in CM-treated animals when compared to the other groups ( $p<0.01$ vs control and DM-treated) (Figure 3A-C). In the presence of palmitoyl-carnitine, no significant differences were observed in state 4 respiration rates between different groups (Figure 3B). The quality of mitochondrial preparations was assessed by the respiratory control ratio (RCR) (Figure 3D). 

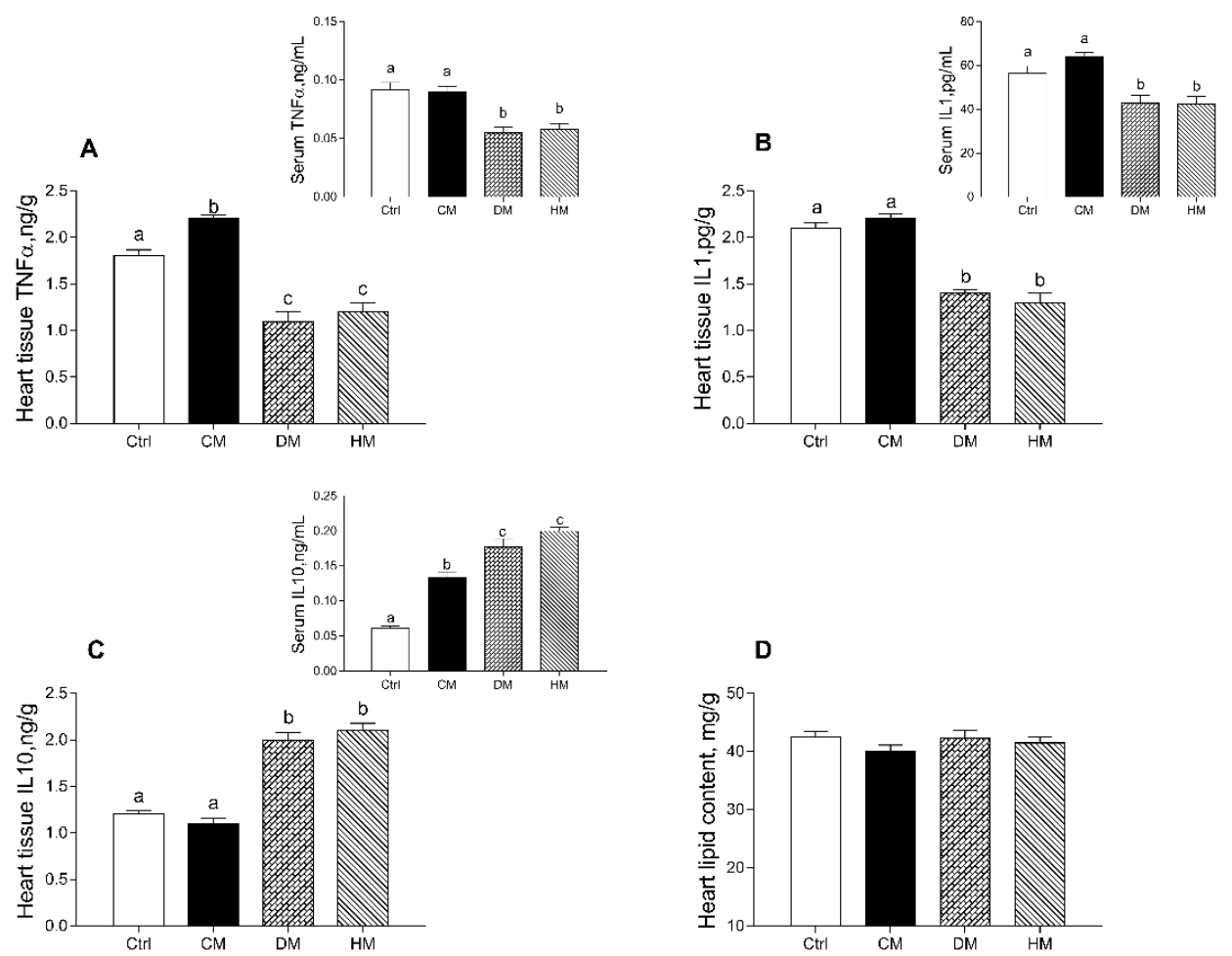

Figure 2. Cow milk (CM), donkey milk (DM) or human milk (HM) diet supplementation differently modulates inflammation in rat serum and cardiac tissue. Proinflammatory cytokines, such as tumor necrosis factor (TNF- $\alpha)($ A) and interleukin-1 (IL-1) (B) and anti-inflammatory marker interleukin-10 (IL-10) (C) were measured in serum and heart (upper panels). Total lipid content (D) was determined in heart tissue. Data were expressed as the means \pm SEM $n=7$ animals/group. Different letters $(\mathrm{a}, \mathrm{b}, \mathrm{c})$ on top of the bars indicate statistically significant differences $(p<0.05)$ among groups.
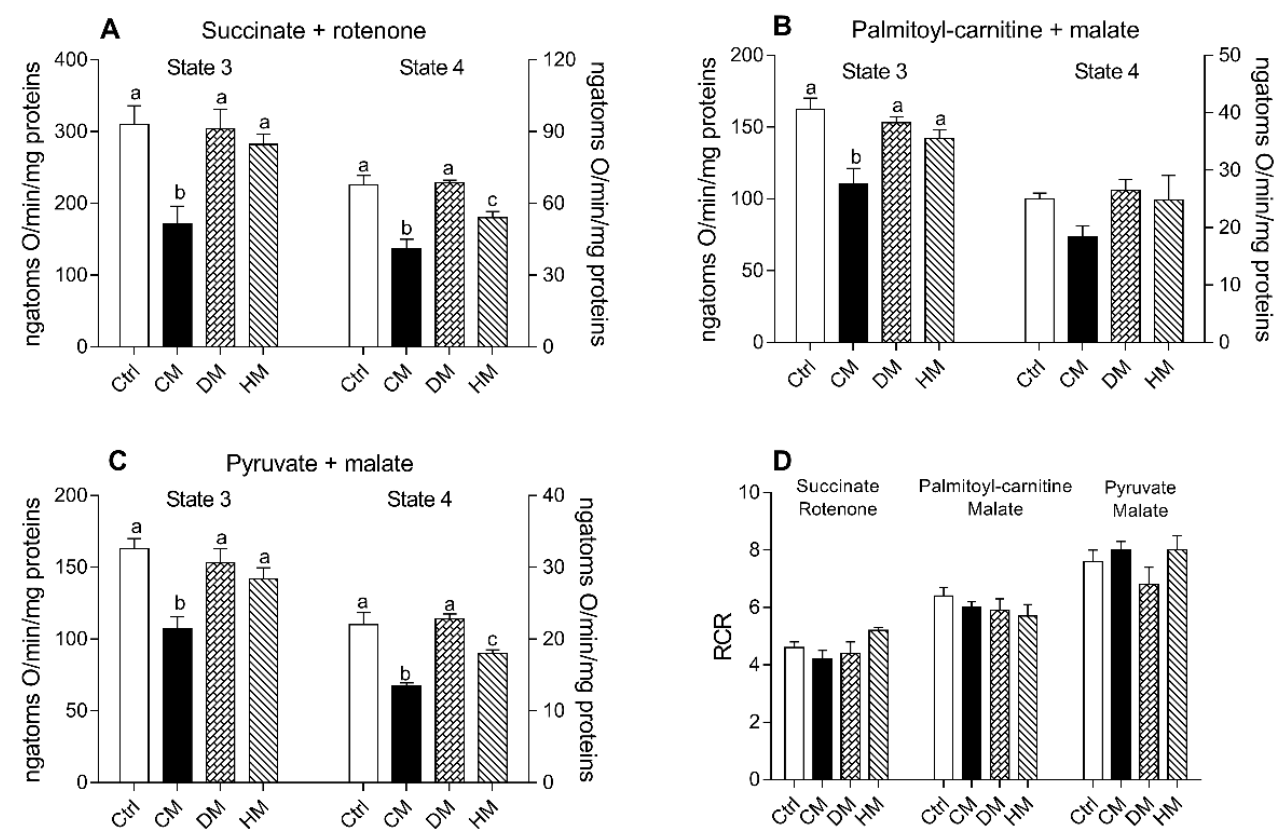

Figure 3. Cow milk (CM), donkey milk (DM) or human milk (HM) diet supplementation modulates the rat cardiac mitochondrial oxidative capacity. The mitochondrial respiration rates were evaluated in the presence of succinate-rotenone (A) or palmitoyl-carnitine-malate (B) or pyruvate-malate (C) as substrates, in the presence (state 3) or absence (state 4) of ADP. Relative respiratory control ratios (RCR) were reported (D). Data were expressed as the means \pm SEM n $=7$ animals $/$ group. Different letters $(a, b, c)$ on top of the bars indicate statistically significant differences $(p<0.05)$ among groups. 


\subsection{Cardiac Redox Status Is Modulated by Different Milk Administration in Rats}

The DM administration decreased mitochondrial $\mathrm{H}_{2} \mathrm{O}_{2}$ release compared to $\mathrm{CM}$ or HM treatments $(p<0.05)$ (Figure 4A). DM- and HM-treated groups showed a significantly lower SOD activity than control $(p<0.01)$ or CM-treated animals $(p<0.05)$ (Figure 4B). In addition, CM-supplemented rats showed a significant reduction in CAT activity as compared to other groups $(p<0.001)$ (Figure $4 \mathrm{C})$ and exhibited the highest lipid peroxidation index (MDA) $(p<0.01 \mathrm{vs} \mathrm{control;} p<0.001 \mathrm{vs.} \mathrm{DM-} \mathrm{and} \mathrm{HM),} \mathrm{whereas} \mathrm{the} \mathrm{lowest} \mathrm{values}$ were detected in DM- and HM-animals (Figure 4D).
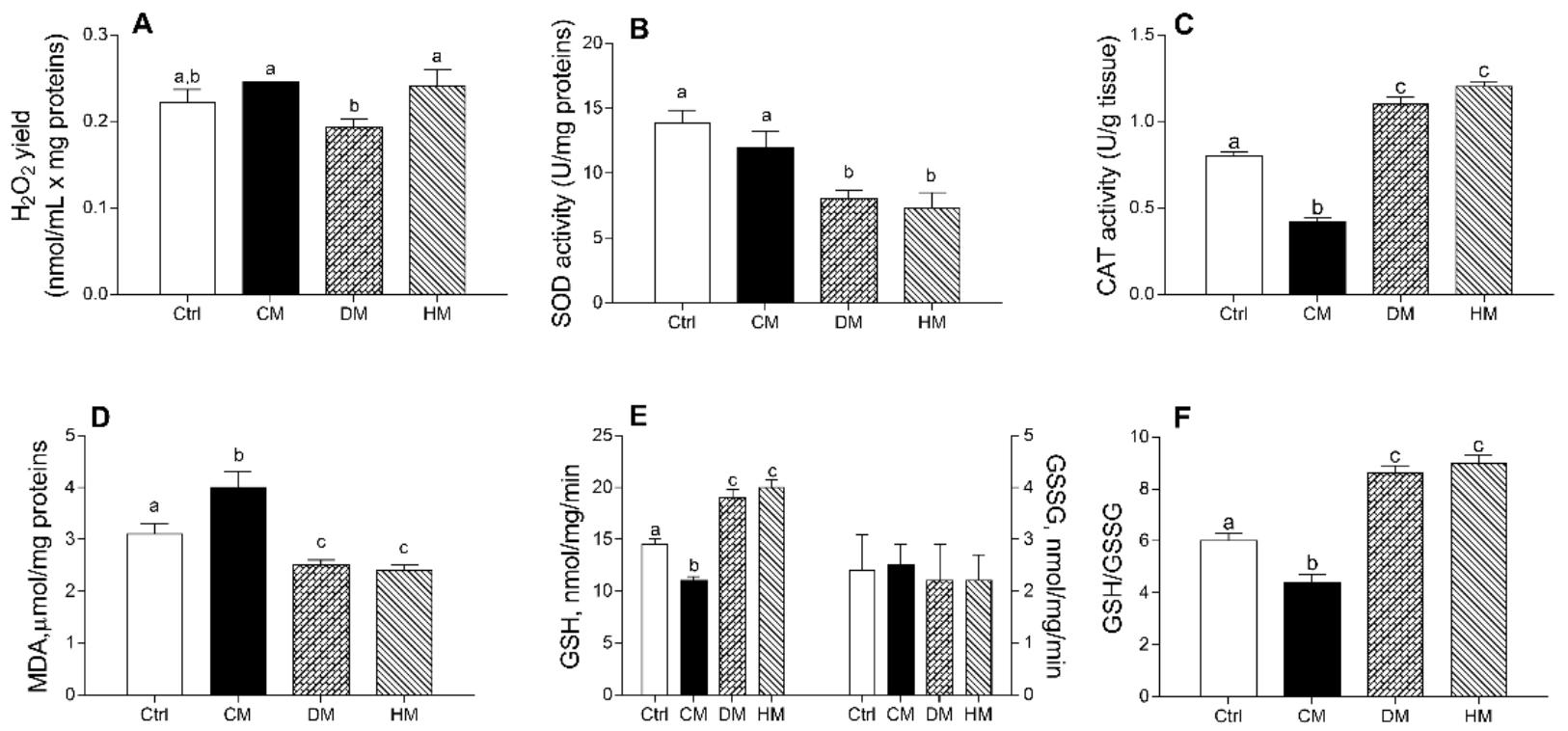

Figure 4. Cow milk (CM), donkey milk (DM) or human milk (HM) diet supplementation exhibits different efficacy in modulating rat cardiac mitochondrial ROS production, enzymatic antioxidant defenses, lipid peroxidation and cellular GSH/GSSG ratio. Mitochondrial $\mathrm{H}_{2} \mathrm{O}_{2}$ yield (A), superoxide dismutase (SOD) (B) and catalase (CAT) activities (C) were reported. Lipid peroxidation index (MDA) (D), GSH and GSSG levels (E,F) were determined in heart homogenates. Data were expressed as the means \pm SEM $n=7$ animals/group. Different letters $(a, b, c)$ on top of the bars indicate statistically significant differences $(p<0.05)$ among groups.

Diet supplementation with DM or HM improved the antioxidant state. Indeed, while no differences in GGSG content was observed between different groups, GSH levels significantly decreased in CM- $(p<0.01)$ and increased in DM- or HM-treated animals $(p<0.001)$ when compared to controls (Figure 4E), resulting in the lowest GSH/GSSG ratio in CM-group ( $p<0.01$ vs. control) and in the highest value in the DM- and HM-treated groups $(p<0.001)$ (Figure $4 \mathrm{~F})$.

3.5. Distinct Milk Administration Differently Modulates Cardiac Expression of the Mitochondrial Respiratory Chain Complexes Genes

To investigate the effect of milk diet supplementation on expression levels of genes encoding subunits of mitochondrial respiratory chain complex, the transcript levels of two subunits of the complex I-II and of five subunits of complex III-IV were evaluated by RTPCR. mRNA levels of NDUFB6 and SDHA, components of complexes I and II respectively, COX I and UQCRC I did not change in the treated groups compared with controls, although a non-significant increase was observed in CM treated rats (Figure 5A-D). The expression levels of UQCRC II, COX IV, ATPase ( $p<0.001, \mathrm{CM}$ vs. control) (Figure 5E-G) and regulators of mitochondrial biogenesis PGC-1alpha $(p<0.05)$ and NRF1 $(p<0.001)$ (Figure 5H,I) were significantly increased in rats treated with $\mathrm{CM}$ compared with other groups. 

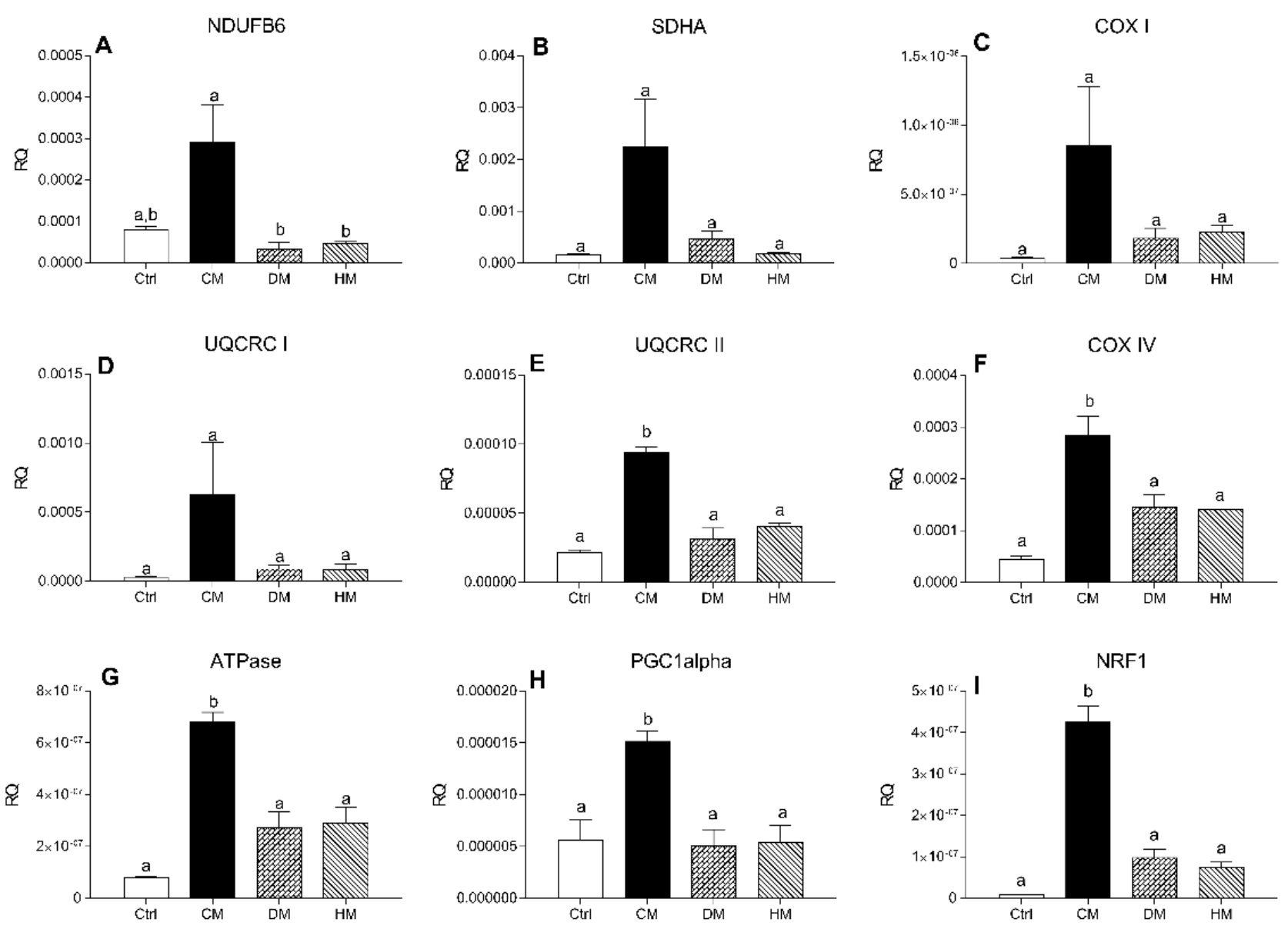

Figure 5. mRNA levels of complex I-II subunits in heart tissue. The transcription levels of NDUFB6 (A), SDHA (B), COX-I (C), UQCRC-I (D), UQCRC-II (E), COX-IV (F), ATPase (G), PGC-1alpha (H) and NRF (I) genes were evaluated by Real-Time PCR. Results are expressed as relative quantification (RQ) and are the mean of three independent experiments $(n=3 /$ group). Different letters $(a, b)$ on top of the bars indicate statistically significant differences $(p<0.05)$ among groups.

\subsection{Distinct Milk Administration Affects the Histological Features of the Heart Muscle Fibers}

Cardiac fibers of control (Figure 6A,B) and DM- (Figure 6C,D) and HM-treated animals (Figure 6E,F) showed normal morphology. Specifically, from the analysis of Mallory trichrome stained longitudinal sections of hearts emerged the presence, in these experimental groups, of regular-shaped cardiomyocytes, in which the transverse streaks and regular intercellular spaces are evident; in the intercellular spaces, collagen fibers appear bluestained. In the sections of animals supplemented with DM, the presence in the intercellular spaces of cells with the typical adipocyte shape is also evident (Figure 6D). On the contrary, heart sections from animals supplemented with $\mathrm{CM}$ (Figure 6G,H) showed hypertrophic cardiomyocytes, in which transverse banding and intercalated discs are detectable. In these animals, due to the increase in the volume of cardiomyocytes, the intercellular spaces appear strongly reduced.

\subsection{Distinct Milk Administration Modifies Lipid Profile and Endocannabinoidome in the Cardiac Tissue}

Fatty acid profile shows a general higher incorporation of $n-3$ highly polyunsaturated fatty acids (HPUFAs), and in particular docosahexaenoic acid (DHA), in hearts of rats treated with DM and HM (Table 2), while $N$-acylethanolamines (NAE) profile shows a significant decrease of $\mathrm{N}$-arachidonoylethanolamide (AEA) and $\mathrm{N}$-docosahexaenoylethanolamide (DHEA) in the same groups (Table 3). 


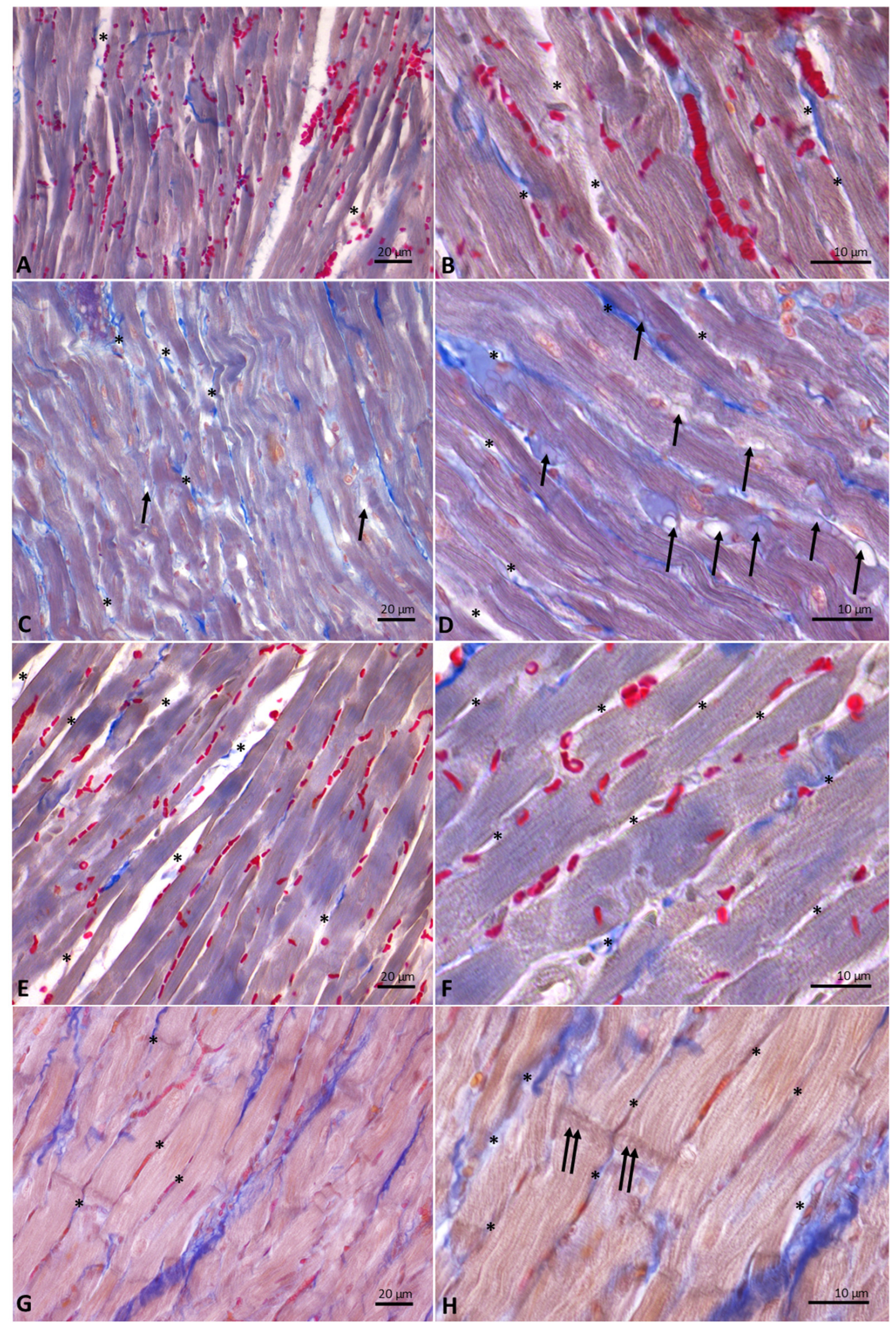

Figure 6. Longitudinal sections of rat hearts stained with Mallory's trichrome stain. (A,B): controls. (C,D): donkey milk (DM) diet supplementation. (E,F): human milk (HM) diet supplementation. $(\mathbf{G}, \mathbf{H})$ : cow milk $(\mathrm{CM})$ diet supplementation. Legends: arrow, adipocyte; asterisk, intercellular space, double arrow, intercalated discs. Scale bar: $(\mathbf{A}, \mathbf{C}, \mathbf{E}, \mathbf{G}), 20 \mu \mathrm{m}$; (B,D,F,H), $10 \mu \mathrm{m}$. 
Table 2. Changes of fatty acid profile in heart of rats fed with CM, DM or HM diet supplementation.

\begin{tabular}{|c|c|c|c|c|}
\hline nmol/g Tissue & Control & CM-Treated & DM-Treated & HM-Treated \\
\hline ALA,18:3n3 & $258.57 \pm 21.35$ & $235.50 \pm 38.53$ & $262.00 \pm 26.20$ & $238.72 \pm 23.99$ \\
\hline EPA,20:5n3 & $180.42 \pm 12.61^{\mathrm{a}, \mathrm{b}}$ & $149.34 \pm 12.61^{\mathrm{a}}$ & $187.97 \pm 24.62^{b}$ & $183.21 \pm 6.77^{\mathrm{a}, \mathrm{b}}$ \\
\hline DPA,22:5n3 & $902.76 \pm 62.55^{a, b}$ & $831.42 \pm 90.42^{a}$ & $974.87 \pm 86.88^{a, b}$ & $906.75 \pm 42.24^{b}$ \\
\hline DHA,22:6n3 & $8938.36 \pm 436.47^{a}$ & $9616.58 \pm 158.38^{a}$ & $11,132.58 \pm 336.50^{b}$ & $10,290.31 \pm 295.78^{a, b}$ \\
\hline LA,18:2n6 & $21,911.79 \pm 372.92^{a, b, c}$ & $18,689.10 \pm 902.29^{b, c}$ & $23,642.50 \pm 847.93^{a}$ & $19,785.46 \pm 379.40^{b}$ \\
\hline ETA,20:3n6 & $632.89 \pm 60.42$ & $674.66 \pm 32.68$ & $653.45 \pm 60.58$ & $747.09 \pm 41.46$ \\
\hline AA,20:4n6 & $13,445.11 \pm 404.61$ & $13,201.11 \pm 651.81$ & $13,963.23 \pm 1144.02$ & $14,381.91 \pm 573.23$ \\
\hline DPA,22:5n6 & $604.56 \pm 31.19^{a}$ & $693.92 \pm 7.68^{b}$ & $655.69 \pm 11.55^{a, b}$ & $676.23 \pm 25.97^{a, b}$ \\
\hline DTA,22:4n6 & $756.65 \pm 59.39$ & $777.80 \pm 58.09$ & $761.79 \pm 60.48$ & $730.88 \pm 35.32$ \\
\hline $14: 1 \mathrm{n} 7$ & $156.33 \pm 10.34^{a}$ & $157.32 \pm 3.01^{\mathrm{a}}$ & $101.23 \pm 1.50^{b}$ & $115.61 \pm 8.00^{a}$ \\
\hline POA,16:1n7 & $647.98 \pm 71.88$ & $678.39 \pm 189.96$ & $546.32 \pm 90.22$ & $461.51 \pm 70.58$ \\
\hline OA,18:1n9 & $7238.21 \pm 296.97$ & $6939.20 \pm 820.32$ & $7438.93 \pm 771.68$ & $7596.36 \pm 375.55$ \\
\hline 18:1n7 & $5054.95 \pm 167.26$ & $4401.26 \pm 324.03$ & $4313.26 \pm 200.96$ & $4433.04 \pm 123.26$ \\
\hline $8: 0$ & $106.20 \pm 17.43$ & $136.47 \pm 17.36$ & $99.76 \pm 17.58$ & $141.32 \pm 31.38$ \\
\hline $10: 0$ & $42.73 \pm 9.50$ & $68.62 \pm 27.13$ & $44.59 \pm 11.27$ & $45.39 \pm 8.22$ \\
\hline 12:0 & $58.49 \pm 20.13$ & $106.85 \pm 25.12$ & $29.31 \pm 3.36$ & $107.30 \pm 16.65$ \\
\hline MA,14:0 & $218.29 \pm 21.86^{a}$ & $467.59 \pm 57.14^{b}$ & $228.89 \pm 19.40^{\mathrm{a}, \mathrm{b}}$ & $251.69 \pm 15.93^{a, b}$ \\
\hline PA,16:0 & $13,368.47 \pm 549.03$ & $12,908.57 \pm 612.14$ & $12,195.98 \pm 505.56$ & $12,508.22 \pm 357.77$ \\
\hline $17: 0$ & $494.22 \pm 49.96$ & $418.46 \pm 44.82$ & $320.53 \pm 17.76$ & $297.69 \pm 33.37$ \\
\hline SA,18:0 & $14,044.16 \pm 383.02$ & $13,532.07 \pm 387.28$ & $13,013.23 \pm 471.47$ & $14,4424.90 \pm 327.01$ \\
\hline
\end{tabular}

Data represent mean \pm SEM for 7 animals per group and are expressed as nmoles/g tissue. Different superscripted letters indicate statistically significant differences $(p<0.05)$ (one-way ANOVA nonparametric measures with Kruskal-Wallis test). ALA, $\alpha$-linolenic acid; EPA, eicosapentaenoic acid; DPA, docosapentaenoic acid; DHA, docosahexaenoic acid; DTA, docosatetraenoic acid; LA, linoleic acid; ETA, eicosatrienoic acid; AA, arachidonic acid; POA, palmitoleic acid; OA, oleic acid; MA, myristic acid; PA, palmitic acid; SA, stearic acid. Different letters $(a, b, c)$ next to values indicate statistically significant differences $(p<0.05)$.

Table 3. Changes of endocannabinoidome profile in heart of rats fed with CM, DM or HM diet supplementation.

\begin{tabular}{ccccc}
\hline pmol/g Tissue & Control & CM-Treated & DM-Treated & HM-Treated \\
\hline POEA & $12.53 \pm 2.69^{\mathrm{a}, \mathrm{b}}$ & $7.80 \pm 0.52^{\mathrm{b}}$ & $13.75 \pm 1.13^{\mathrm{a}}$ & $9.34 \pm 1.00^{\mathrm{a}, \mathrm{b}}$ \\
\hline AEA & $55.56 \pm 3.55^{\mathrm{a}}$ & $45.74 \pm 3.55^{\mathrm{a}, \mathrm{b}}$ & $21.54^{\mathrm{b}} \pm 1.84^{\mathrm{c}}$ & $27.34^{\mathrm{a}} \pm 0.36^{\mathrm{b}}$ \\
\hline DHEA & $126.03 \pm 3.94^{\mathrm{a}}$ & $132.81 \pm 4.73^{\mathrm{a}}$ & $78.59 \pm 6.18^{\mathrm{b}}$ & $97.92^{\mathrm{b}} \pm 5.65^{\mathrm{a}, \mathrm{b}}$ \\
\hline LEA & $100.97 \pm 7.36$ & $105.19 \pm 6.25$ & $108.78 \pm 8.01$ & $103.53 \pm 10.09$ \\
\hline PEA & $140.32 \pm 9.19$ & $129.41 \pm 11.78$ & $125.08 \pm 12.16$ & $144.48 \pm 17.80$ \\
\hline OEA & $169.75 \pm 11.26$ & $153.75 \pm 7.07$ & $169.28 \pm 11.06$ & $171.49 \pm 13.82$ \\
\hline DTEA & $9.70 \pm 1.20$ & $11.44 \pm 3.19$ & $7.23 \pm 0.73$ & $9.05 \pm 1.28$ \\
\hline SEA & $69.19 \pm 4.08$ & $68.43 \pm 3.38$ & $71.08 \pm 5.83$ & $69.19 \pm 7.58$ \\
\hline 2AG & $4251.89 \pm 307.50$ & $5076.72 \pm 508.05$ & $3446.42 \pm 217.36$ & $4662.21 \pm 773.63$ \\
\hline 2LG & $15,045.36 \pm 1.472 .329$ & $17,714.40 \pm 1513.11$ & $8383.01 \pm 1269.33$ & $14,721.11 \pm 3523.24$ \\
\hline 2PG & $287,635.54 \pm 126360.68$ & $251,591.30 \pm 64894.94$ & $250,790.67 \pm 90116.73$ & $294,106.10 \pm 72879.22$ \\
\hline IOG & $20,974.23 \pm 2234.46$ & $29,883.32 \pm 3591.74$ & $9739.69 \pm 1504.49$ & $25,774.59 \pm 4962.39$ \\
\hline
\end{tabular}

Data represent mean \pm SEM for 7 animals per group and are expressed as pmoles/g tissue. Different superscripted letters indicate statistically significant differences $(p<0.05)$ (one-way ANOVA nonparametric measures with Kruskal-Wallis test). AEA, Narachidonoylethanolamide or anandamide; DHEA, N-docosahexaenoylethanolamide; DTEA, Docosatetraenoylethanolamide; LEA, $\mathrm{N}$-linoleoylethanolamide; OEA, $\mathrm{N}$-oleoylethanolamide; PEA, $\mathrm{N}$-palmitoylethanolamine; POEA, palmitoleylethanolamide; SEA, $\mathrm{N}$ stearoylethanolamide; 2AG, 2-arachidonoyl glycerol; 2LG, 2-linoleoyl glycerol, 2PG, 2-palmitoyl glycerol; 2OG, 2-oleoyl glycerol. Different letters $(\mathrm{a}, \mathrm{b})$ next to values indicate statistically significant differences $(p<0.05)$. 


\section{Discussion}

The investigation of the biological mechanisms linking nutrition, antioxidants properties and cardiovascular protection continues to be a great challenge. Our data demonstrated, for the first time, that the administration of milk from different animal species in rat model system, differently modulates heart lipid metabolism, inflammation and oxidative state by affecting the regulation of the mitochondrial function. These results are particularly relevant since mitochondria play a crucial role in cardiac energy output and are critically important in energy-demanding cardiac functions [54]. It is noteworthy that the role of mitochondria is not limited to bioenergetic regulation, but it extends to ion homeostasis, apoptosis and synthesis of key molecules related to inflammation and redox state [55]. The heart, besides liver and skeletal muscle, is one of the most metabolically active organs in the body since it needs intense energy production to generate the contractile force. Therefore, cardiac mitochondria represent the key organelles for the maintenance of cardiac health, and the control of mitochondrial function is a crucial step in the prevention/therapy of cardiac diseases [56].

We previously demonstrated that the diet supplementation of CM, DM or HM in rats, differently regulated metabolic and inflammatory parameters attributable to the modulation of hepatic and muscular mitochondrial function $[37,38]$. These data validated the alteration of mitochondrial function as part of the wide spectrum of metabolic changes induced by nutrition-dependent low-grade inflammation [57]. In particular, DM and $\mathrm{HM}$ are able to improve the use of fat as metabolic fuel for hepatic and skeletal muscle mitochondria, decreasing the accumulation of body lipids [37,38]. Thus, DM and HM, compared to CM, yield similar metabolizable energy, but increased energy expenditure and consequent decrease in body weight and body lipid gain [37]. We hypothesized that the metabolic effects of HM and DM depend, at least in part, on their higher content in PUFA omega-3, which are known to be involved in energy balance, lipid metabolism and prooxidant status, through the modulation of mitochondrial functions [30]. On the other hand, the increased inflammatory state and oxidative stress of CM-treated rats, may be related to the high concentrations of saturated fatty acids in CM [58]. However, we cannot exclude that the increased body weight gain of $\mathrm{CM}$ animals can contribute to their metabolic state. Here, we confirmed the influence of milk supplementation from different animal species in the cytokine's levels of rat serum and heart tissue, showing that DM and HM administration decreases TNF- $\alpha$ and IL- 1 in both serum and heart, and increases IL-10, an anti-inflammatory mediator. TNF $\alpha$ and IL-1 $\beta$, together with the reactive nitrogen intermediate nitric oxide, may induce mitochondrial damage [59,60]. Moreover, TNF $\alpha$ and IL-1 $\beta$ decrease the activity of mitochondrial respiratory complex I, ATP production and mitochondrial membrane potential. These mediators also induce the accumulation of significant amounts of ROS [61,62]. Therefore, mitochondrial dysfunctions and inflammation are tightly interlinked processes promoting a vicious inflammatory cycle and increased oxidative stress [63].

By analyzing the modulation of heart mitochondrial function following the administration of milk from different animal species, we observed that CM-fed rats exhibited decreased respiratory capacity and decreased fatty acid oxidation rate as compared to other groups. Indeed, state 3 respiration significantly decreased both in presence of NADHlinked (pyruvate) and FADH-linked (succinate) substrate. A decrease in succinate State 3 respiration may be due to defects in the activity of substrate oxidation reactions (complex II, complex III, complex IV and dicarboxylate carrier) and/or in the activity of the phosphorylation reactions (ANT, ATP synthase and phosphate carrier). However, the gene expression analysis conducted in milk-treated rats suggested that the observed mitochondrial alteration in CM-fed animals could be compensated by upregulation of genes related to mitochondrial biogenesis (PGC-1alpha and NRF1) and an increase of the transcript levels of the mitochondrial subunits of the respiratory chain complexes. The role of PGC-1alpha in the control of mitochondrial number and function in cardiac tissue is still controversial [64]. Some studies have suggested that overexpression of PGC-1alpha 
may be beneficial for the heart under pressure load [65]. However, the overexpression of PGC-1alpha may not improve mitochondrial function and myocardial contractile function [66]. The animals of $\mathrm{CM}$-fed group showed a decreased fatty acid oxidation rate and hypertrophic cardiomyocytes, although no significant differences were found in cardiac lipid content among differently treated groups. These results are in line with previous study demonstrating that cardiac hypertrophy results in a downregulation of fatty acid oxidation enzyme expression and reduced capacity for mitochondrial oxidation of fats [67]. Therefore, it can be hypothesized that PGC-1alpha overexpression is aimed at rescuing the decreased mitochondrial oxidative capacity in $\mathrm{CM}$ group.

These results confirm that cardiomyocytes develop well-coordinated quality control mechanisms that maintain overall mitochondrial health. Cardiac mitochondria are also the primary source of ROS, which contribute to mitochondrial dysfunction, cardiomyocyte damage and heart failure [68-71]. ROS production is typically controlled by intracellular and intramitochondrial scavenging systems. Pathological ROS levels in the heart typically occur when ROS production outpaces endogenous scavenging capacity, leading to damaged proteins and lipids, triggering cell-death cascades and evoking synchronized collapses in the cellular energy grid [72]. In this study, pathological levels of ROS were not found in any milk-treated group. However, our data showed that DM and HM administration decreased mitochondrial $\mathrm{H}_{2} \mathrm{O}_{2}$ release and increased catalase activity leading to higher GSH/GSSG ratio, although SOD activity decreased. Accordingly, in the same groups of animals it was observed a decreased lipid peroxidation, indicated by the reduced MDA levels. Conversely, the impairment in mitochondrial function observed in CM-fed rats was corroborated by the altered redox status as demonstrated by the lowest GSH/GSSG ratio and the reduction in catalase activity. The compromised oxidative state in CM group is mirrored in higher MDA levels in the heart of these animals. These increased levels of MDA are particularly relevant since the lipid peroxidation is the first step on the way to the development of CVD [73]. It is noteworthy that fatty acids accumulating in the vicinity of mitochondria are particularly vulnerable to ROS-induced lipid peroxidation, which has in turn toxic effects on mtDNA, RNA and proteins of the mitochondrial machinery, leading to mitochondrial dysfunction [74].

Fat cells were visualized in the intercellular spaces of some area of heart from animals fed with DM. Fatty acids are an important fuel source for heart and skeletal muscle, providing over $70 \%$ of the energy needs for cardiac functions [75]. In healthy subjects it was demonstrated that the aging, the short-term caloric restriction and starvation provoked a dose-dependent increase in myocardial triglyceride content and a decrease in diastolic function [76]. Cardiac and perivascular adipose tissue may act as a local energy supplier and/or as a buffer against toxic levels of free fatty acids in the myocardium and the arterial circulation [77]. Indeed, it has been hypothesized that it initially serves to compartmentalize the toxic lipid species, but subsequently promotes cardiac damage [76]. Thus, the cardiac and perivascular fat depots, in a healthy situation, exert a protective modulation of vascular function, but when they expand, become lipotoxic, prothrombotic and proinflammatory organ. The adipose tissue, establishing intense crosstalk with cardiac tissue, may shift from being protective to being detrimental, depending on its residual substrate buffering capacity and inflammatory status. In addition, fat around blood vessels and heart may play a supportive role, not only from a mechanical point of view, but also as a vasocrine and paracrine source of cytokines increasing the release of the anti-inflammatory cytokine IL-10 and decreasing the release of IL-1 and TNF $\alpha$, as we observed in DM-fed group.

Unexpectedly, analysis of the NAE showed reduction of $\mathrm{N}$-docosahexaenoylethanolamide (DHEA) in rats fed DM, and reduction of $N$-arachidonoylethanolamide (AEA) in rats fed DM or HM, despite arachidonic acid, precursor for AEA, did not change in both groups and DHA, precursor for DHEA, increased significantly. These data suggest that differences in AEA and DHEA might be ascribed to their degradation by fatty acid amide hydrolase (FAAH) [78]. In addition, we previously found that in skeletal muscle of rats fed DM and HM the levels of OEA increased [38], while no difference was observed in the heart of the same 
groups of animals. These results may also be explained by an increased FAAH activity in the heart [79]. It is noteworthy that AEA is a ligand of cannabinoid type 1 (CB1) and transient potential vanilloid 1 (TRPV1) receptors, and the role of CB1 and AEA in the heart is quite controversial [80]. Therefore, further studies are needed to evaluate whether and how these changes may influence heart function.

\section{Conclusions}

Our data demonstrated, for the first time, that the administration of cow, donkey or human milk differently modulates heart lipid metabolism, inflammation and oxidative state by affecting heart mitochondrial function. The different efficacy of various types of milk in modulating cardiac mitochondrial ROS production, enzymatic antioxidant defenses and lipid storage, utilization and peroxidation, underlines the functional role of different milk in metabolic and inflammatory homeostasis. This study strengthens the interlink between mitochondrial metabolic flexibility, lipid storage and redox status as control mechanisms for the maintenance of cardiovascular health.

Author Contributions: Conceptualization, L.G. and M.P.M.; Data curation, G.T., F.C., D.S. and E.M.; Methodology, G.T., F.C., G.C., L.R., A.C., D.S., E.M. and R.S.; Resources, L.B. and L.P.; Supervision, P.B., G.I., L.G., S.B., M.C. and M.P.M.; Validation, L.G., S.B., M.C. and M.P.M.; Visualization, G.T. and L.R.; Writing—original draft, G.T. and M.P.M.; Writing—review and editing, G.T., P.B., R.S., S.B., M.C. and M.P.M. All authors have read and agreed to the published version of the manuscript.

Funding: This research received no external funding.

Institutional Review Board Statement: The study was conducted according to the guidelines of the Declaration of Helsinki, approved by the Institutional Animal Care and Use Committee (CSV) of the University of Naples Federico II and authorized by the Italian Ministry of Health under protocol no. 97/2019-PR, approval date 4 February 2019.

Informed Consent Statement: Not applicable.

Data Availability Statement: Data is contained within this article.

Acknowledgments: The authors thank Roberta Scognamiglio (University of Naples Federico II, Naples, Italy) and Silvia Di Chio (ASST Fatebenefratelli-Sacco, Milan, Italy) for the invaluable technical assistance.

Conflicts of Interest: The authors declare no conflict of interest.

\section{References}

1. González-Muniesa, P.; Mártinez-González, M.A.; Hu, F.B.; Després, J.P.; Matsuzawa, Y.; Loos, R.J.F.; Moreno, L.A.; Bray, G.A.; Martinez, J.A. Obesity. Nat. Rev. Dis. Primers 2017, 3, 17034. [CrossRef]

2. Smith, R.L.; Soeters, M.R.; Wüst, R.C.I.; Houtkooper, R.H. Metabolic Flexibility as an Adaptation to Energy Resources and Requirements in Health and Disease. Endocr. Rev. 2018, 39, 489-517. [CrossRef]

3. Gao, A.W.; Cantó, C.; Houtkooper, R.H. Mitochondrial response to nutrient availability and its role in metabolic disease. EMBO Mol. Med. 2014, 6, 580-589. [CrossRef]

4. Bhatti, J.S.; Bhatti, G.K.; Reddy, P.H. Mitochondrial dysfunction and oxidative stress in metabolic disorders-A step towards mitochondria based therapeutic strategies. Biochim. Biophys. Acta Mol. Basis Dis. 2017, 1863, 1066-1077. [CrossRef]

5. Ingwall, J.S.; DeLuca, M.; Sybers, H.D.; Wildenthal, K. Fetal mouse hearts: A model for studying ischemia. Proc. Natl. Acad. Sci. USA 1975, 72, 2809-2813. [CrossRef] [PubMed]

6. Hearse, D.J.; Stewart, D.A.; Braimbridge, M.V. Hypothermic arrest and potassium arrest: Metabolic and myocardial protection during elective cardiac arrest. Circ. Res. 1975, 36, 481-489. [CrossRef] [PubMed]

7. Hearse, D.J. Oxygen deprivation and early myocardial contractile failure: A reassessment of the possible role of adenosine triphosphate. Am. J. Cardiol. 1979, 44, 1115-1121. [CrossRef]

8. Gresser, M.; Cardon, J.; Rosen, G.; Boyer, P.D. Demonstration and quantitation of catalytic and noncatalytic bound ATP in submitochondrial particles during oxidative phosphorylation. J. Biol. Chem. 1979, 254, 10649-10653. [CrossRef]

9. Kadenbach, B.; Barth, J.; Akgün, R.; Freund, R.; Linder, D.; Possekel, S. Regulation of mitochondrial energy generation in health and disease. Biochim. Biophys. Acta 1995, 1271, 103-109. [CrossRef] 
10. Valkovič, L.; Clarke, W.T.; Schmid, A.I.; Raman, B.; Ellis, J.; Watkins, H.; Robson, M.D.; Neubauer, S.; Rodgers, C.T. Measuring inorganic phosphate and intracellular $\mathrm{pH}$ in the healthy and hypertrophic cardiomyopathy hearts by in vivo 7T. J. Cardiovasc. Magn. Reson. 2019, 21, 19. [CrossRef]

11. Nijtmans, L.G.; Henderson, N.S.; Attardi, G.; Holt, I.J. Impaired ATP synthase assembly associated with a mutation in the human ATP synthase subunit 6 gene. J. Biol. Chem. 2001, 276, 6755-6762. [CrossRef] [PubMed]

12. Szendrei, L.; Turoczi, T.; Kovacs, P.; Vecsernyes, M.; Das, D.K.; Tosaki, A. Mitochondrial gene expression and ventricular fibrillation in ischemic/reperfused nondiabetic and diabetic myocardium. Biochem. Pharmacol. 2002, 63, 543-552. [CrossRef]

13. Carbajo, R.J.; Silvester, J.A.; Runswick, M.J.; Walker, J.E.; Neuhaus, D. Solution structure of subunit F(6) from the peripheral stalk region of ATP synthase from bovine heart mitochondria. J. Mol. Biol. 2004, 342, 593-603. [CrossRef]

14. Chen, D.; Li, X.; Zhang, L.; Zhu, M.; Gao, L. A high-fat diet impairs mitochondrial biogenesis, mitochondrial dynamics, and the respiratory chain complex in rat myocardial tissues. J. Cell Biochem. 2018, 119, 9602. [CrossRef] [PubMed]

15. Gambardella, J.; Sorriento, D.; Ciccarelli, M.; Del Giudice, C.; Fiordelisi, A.; Napolitano, L.; Trimarco, B.; Iaccarino, G.; Santulli, G. Functional Role of Mitochondria in Arrhythmogenesis. Adv. Exp. Med. Biol. 2017, 982, 191-202. [CrossRef]

16. Sorriento, D.; Gambardella, J.; Fiordelisi, A.; Trimarco, B.; Ciccarelli, M.; Iaccarino, G.; Santulli, G. Mechanistic Role of Kinases in the Regulation of Mitochondrial Fitness. Adv. Exp. Med. Biol. 2017, 982, 521-528. [CrossRef]

17. Sorriento, D.; Gambardella, J.; Fiordelisi, A.; Iaccarino, G.; Illario, M. GRKs and $\beta$-Arrestins: "Gatekeepers" of Mitochondrial Function in the Failing Heart. Front. Pharmacol. 2019, 10, 64. [CrossRef]

18. Franco, A.; Sorriento, D.; Gambardella, J.; Pacelli, R.; Prevete, N.; Procaccini, C.; Matarese, G.; Trimarco, B.; Iaccarino, G.; Ciccarelli, M. GRK2 moderates the acute mitochondrial damage to ionizing radiation exposure by promoting mitochondrial fission/fusion. Cell Death Discov. 2018, 4, 25. [CrossRef]

19. Sorriento, D.; Ciccarelli, M.; Santulli, G.; Illario, M.; Trimarco, B.; Iaccarino, G. Trafficking GRK2: Cellular and Metabolic consequences of GRK2 subcellular localization. Transl. Med. UniSa 2014, 10, 3-7.

20. Nauta, A.J.; Ben Amor, K.; Knol, J.; Garssen, J.; van der Beek, E.M. Relevance of pre- and postnatal nutrition to development and interplay between the microbiota and metabolic and immune systems. Am. J. Clin. Nutr. 2013, 98, 586S-593S. [CrossRef] [PubMed]

21. Guardamagna, O.; Abello, F.; Cagliero, P.; Lughetti, L. Impact of nutrition since early life on cardiovascular prevention. Ital. J. Pediatr. 2012, 38, 73. [CrossRef]

22. Parikh, N.I.; Hwang, S.J.; Ingelsson, E.; Benjamin, E.J.; Fox, C.S.; Vasan, R.S.; Murabito, J.M. Breastfeeding in infancy and adult cardiovascular disease risk factors. Am. J. Med. 2009, 122, 656-663.e1. [CrossRef]

23. Rudnicka, A.R.; Owen, C.G.; Strachan, D.P. The effect of breastfeeding on cardiorespiratory risk factors in adult life. Pediatrics 2007, 119, e1107-e1115. [CrossRef]

24. Martin, R.M.; Ness, A.R.; Gunnell, D.; Emmett, P.; Davey Smith, G.; Team, A.S. Does breast-feeding in infancy lower blood pressure in childhood? The Avon Longitudinal Study of Parents and Children (ALSPAC). Circulation 2004, 109, 1259-1266. [CrossRef]

25. Martin, R.M.; Ben-Shlomo, Y.; Gunnell, D.; Elwood, P.; Yarnell, J.W.; Davey Smith, G. Breast feeding and cardiovascular disease risk factors, incidence, and mortality: The Caerphilly study. J. Epidemiol. Community Health 2005, 59, 121-129. [CrossRef] [PubMed]

26. Owen, C.G.; Whincup, P.H.; Gilg, J.A.; Cook, D.G. Effect of breast feeding in infancy on blood pressure in later life: Systematic review and meta-analysis. BMJ 2003, 327, 1189-1195. [CrossRef] [PubMed]

27. Owen, C.G.; Whincup, P.H.; Odoki, K.; Gilg, J.A.; Cook, D.G. Infant feeding and blood cholesterol: A study in adolescents and a systematic review. Pediatrics 2002, 110, 597-608. [CrossRef]

28. Ravelli, A.C.; van der Meulen, J.H.; Osmond, C.; Barker, D.J.; Bleker, O.P. Infant feeding and adult glucose tolerance, lipid profile, blood pressure, and obesity. Dis. Child. 2000, 82, 248-252. [CrossRef] [PubMed]

29. Owen, C.G.; Martin, R.M.; Whincup, P.H.; Davey-Smith, G.; Gillman, M.W.; Cook, D.G. The effect of breastfeeding on mean body mass index throughout life: A quantitative review of published and unpublished observational evidence. Am. J. Clin. Nutr. 2005, 82, 1298-1307. [CrossRef] [PubMed]

30. Lionetti, L.; Cavaliere, G.; Bergamo, P.; Trinchese, G.; De Filippo, C.; Gifuni, G.; Gaita, M.; Pignalosa, A.; Donizzetti, I.; Putti, R.; et al. Diet supplementation with donkey milk upregulates liver mitochondrial uncoupling, reduces energy efficiency and improves antioxidant and antiinflammatory defences in rats. Mol. Nutr. Food Res. 2012, 56, 1596-1600. [CrossRef] [PubMed]

31. Viggiano, E.; Mollica, M.P.; Lionetti, L.; Cavaliere, G.; Trinchese, G.; De Filippo, C.; Chieffi, S.; Gaita, M.; Barletta, A.; De Luca, B.; et al. Effects of an High-Fat Diet Enriched in Lard or in Fish Oil on the Hypothalamic Amp-Activated Protein Kinase and Inflammatory Mediators. Front. Cell Neurosci. 2016, 10, 150. [CrossRef]

32. Cavaliere, G.; Trinchese, G.; Penna, E.; Cimmino, F.; Pirozzi, C.; Lama, A.; Annunziata, C.; Catapano, A.; Mattace Raso, G.; Meli, R.; et al. High-Fat Diet Induces Neuroinflammation and Mitochondrial Impairment in Mice Cerebral Cortex and Synaptic Fraction. Front. Cell Neurosci. 2019, 13, 509. [CrossRef]

33. Qi, Z.; Ding, S. Targeting mitochondrial phenotypes for non-communicable diseases. J. Sport Health Sci. 2016, 5, 155-158. [CrossRef] [PubMed] 
34. Mollica, M.P.; Trinchese, G.; Cimmino, F.; Penna, E.; Cavaliere, G.; Tudisco, R.; Musco, N.; Manca, C.; Catapano, A.; Monda, M.; et al. Milk Fatty Acid Profiles in Different Animal Species: Focus on the Potential Effect of Selected PUFAs on Metabolism and Brain Functions. Nutrients 2021, 13, 1111. [CrossRef]

35. Fontecha, J.; Calvo, M.V.; Juarez, M.; Gil, A.; Martínez-Vizcaino, V. Milk and Dairy Product Consumption and Cardiovascular Diseases: An Overview of Systematic Reviews and Meta-Analyses. Adv. Nutr. 2019, 10, S164-S189. [CrossRef]

36. Khan, I.T.; Nadeem, M.; Imran, M.; Ullah, R.; Ajmal, M.; Jaspal, M.H. Antioxidant properties of Milk and dairy products: A comprehensive review of the current knowledge. Lipids Health Dis. 2019, 18, 41. [CrossRef] [PubMed]

37. Trinchese, G.; Cavaliere, G.; Canani, R.B.; Matamoros, S.; Bergamo, P.; De Filippo, C.; Aceto, S.; Gaita, M.; Cerino, P.; Negri, R.; et al. Human, donkey and cow milk differently affects energy efficiency and inflammatory state by modulating mitochondrial function and gut microbiota. J. Nutr. Biochem. 2015, 26, 1136-1146. [CrossRef] [PubMed]

38. Trinchese, G.; Cavaliere, G.; De Filippo, C.; Aceto, S.; Prisco, M.; Chun, J.T.; Penna, E.; Negri, R.; Muredda, L.; Demurtas, A.; et al. Human Milk and Donkey Milk, Compared to Cow Milk, Reduce Inflammatory Mediators and Modulate Glucose and Lipid Metabolism, Acting on Mitochondrial Function and Oleylethanolamide Levels in Rat Skeletal Muscle. Front. Physiol. 2018,9 , 32. [CrossRef]

39. Mollica, M.P.; Mattace Raso, G.; Cavaliere, G.; Trinchese, G.; De Filippo, C.; Aceto, S.; Prisco, M.; Pirozzi, C.; Di Guida, F.; Lama, A.; et al. Butyrate Regulates Liver Mitochondrial Function, Efficiency, and Dynamics in Insulin-Resistant Obese Mice. Diabetes 2017, 66, 1405-1418. [CrossRef]

40. Lionetti, L.; Mollica, M.P.; Sica, R.; Donizzetti, I.; Gifuni, G.; Pignalosa, A.; Cavaliere, G.; Putti, R. Differential effects of high-fish oil and high-lard diets on cells and cytokines involved in the inflammatory process in rat insulin-sensitive tissues. Int. J. Mol. Sci. 2014, 15, 3040-3063. [CrossRef]

41. Folch, J.; Lees, M.; Sloane Stanley, G.H. A simple method for the isolation and purification of total lipides from animal tissues. J. Biol. Chem. 1957, 226, 497-509. [CrossRef]

42. Chiang, S.; Gessert, C.; Lowry, O. Colorimetric determination of extracted lipids. An adaptation for microgram amounts of lipids obtained from cerumen. Curr. List Med. Lit. Res. Rep. 1957, 33, 56-113.

43. Banni, S.; Carta, G.; Contini, M.S.; Angioni, E.; Deiana, M.; Dessì, M.A.; Melis, M.P.; Corongiu, F.P. Characterization of conjugated diene fatty acids in milk, dairy products, and lamb tissues. J. Nutr. Biochem. 1996, 7, 150-155. [CrossRef]

44. Melis, M.P.; Angioni, E.; Carta, G.; Murru, E.; Scanu, P.; Spada, S.; Banni, S. Characterization of conjugated linoleic acid and its metabolites by RP-HPLC with diode array detector. Eur. J. Lipid Sci. Technol. 2001, 103, 617-621. [CrossRef]

45. Murru, E.; Lopes, P.A.; Carta, G.; Manca, C.; Abolghasemi, A.; Guil-Guerrero, J.L.; Prates, J.A.M.; Banni, S. Different Dietary N-3 Polyunsaturated Fatty Acid Formulations Distinctively Modify Tissue Fatty Acid and N-Acylethanolamine Profiles. Nutrients 2021, 13, 625. [CrossRef] [PubMed]

46. Hartree, E.F. Determination of protein: A modification of the Lowry method that gives a linear photometric response. Anal. Biochem. 1972, 48, 422-427. [CrossRef]

47. Barja, G. Mitochondrial free radical production and aging in mammals and birds. Ann. N. Y. Acad Sci. 1998, 854, 224-238. [CrossRef]

48. Flohé, L.; Otting, F. Superoxide dismutase assays. Methods Enzymol. 1984, 105, 93-104. [CrossRef]

49. Aebi, H. Catalase in vitro. Methods Enzymol. 1984, 105, 121-126. [CrossRef]

50. Lu, H.; Zhang, D.M.; Chen, H.L.; Lin, Y.X.; Hang, C.H.; Yin, H.X.; Shi, J.X. N-acetylcysteine suppresses oxidative stress in experimental rats with subarachnoid hemorrhage. J. Clin. Neurosci. 2009, 16, 684-688. [CrossRef]

51. Bergamo, P.; Maurano, F.; Rossi, M. Phase 2 enzyme induction by conjugated linoleic acid improves lupus-associated oxidative stress. Free Radic. Biol. Med. 2007, 43, 71-79. [CrossRef]

52. Rosati, L.; Agnese, M.; Abagnale, L.; Aniello, F.; Andreuccetti, P.; Prisco, M. The Mussel Mytilus galloprovincialis in the Bay of Naples: New Insights on Oogenic Cycle and Its Hormonal Control. Anat. Rec. 2019, 302, 1039-1049. [CrossRef]

53. Leverve, X.M.; Fontaine, E. Role of substrates in the regulation of mitochondrial function in situ. IUBMB Life 2001, 52, 221-229. [CrossRef]

54. Dai, D.F.; Rabinovitch, P.S. Cardiac aging in mice and humans: The role of mitochondrial oxidative stress. Trends Cardiovasc. Med. 2009, 19, 213-220. [CrossRef]

55. Missiroli, S.; Genovese, I.; Perrone, M.; Vezzani, B.; Vitto, V.A.M.; Giorgi, C. The Role of Mitochondria in Inflammation: From Cancer to Neurodegenerative Disorders. J. Clin. Med. 2020, 9, 740. [CrossRef]

56. Siasos, G.; Tsigkou, V.; Kosmopoulos, M.; Theodosiadis, D.; Simantiris, S.; Tagkou, N.M.; Tsimpiktsioglou, A.; Stampouloglou, P.K.; Oikonomou, E.; Mourouzis, K.; et al. Mitochondria and cardiovascular diseases-from pathophysiology to treatment. Ann. Transl. Med. 2018, 6, 256. [CrossRef] [PubMed]

57. Crispino, M.; Trinchese, G.; Penna, E.; Cimmino, F.; Catapano, A.; Villano, I.; Perrone-Capano, C.; Mollica, M.P. Interplay between Peripheral and Central Inflammation in Obesity-Promoted Disorders: The Impact on Synaptic Mitochondrial Functions. Int. J. Mol. Sci. 2020, 21, 5964. [CrossRef]

58. Huth, P.J.; Park, K.M. Influence of dairy product and milk fat consumption on cardiovascular disease risk: A review of the evidence. Adv. Nutr. 2012, 3, 266-285. [CrossRef] [PubMed] 
59. López-Armada, M.J.; Caramés, B.; Martín, M.A.; Cillero-Pastor, B.; Lires-Dean, M.; Fuentes-Boquete, I.; Arenas, J.; Blanco, F.J. Mitochondrial activity is modulated by TNFalpha and IL-1beta in normal human chondrocyte cells. Osteoarthr. Cartil. 2006, 14, 1011-1022. [CrossRef] [PubMed]

60. Maneiro, E.; López-Armada, M.J.; de Andres, M.C.; Caramés, B.; Martín, M.A.; Bonilla, A.; Del Hoyo, P.; Galdo, F.; Arenas, J.; Blanco, F.J. Effect of nitric oxide on mitochondrial respiratory activity of human articular chondrocytes. Ann. Rheum. Dis. 2005, 64, 388-395. [CrossRef]

61. Guidarelli, A.; Cerioni, L.; Cantoni, O. Inhibition of complex III promotes loss of $\mathrm{Ca}^{2+}$ dependence for mitochondrial superoxide formation and permeability transition evoked by peroxynitrite. J. Cell Sci. 2007, 120, 1908-1914. [CrossRef] [PubMed]

62. Kim, J.; Xu, M.; Xo, R.; Mates, A.; Wilson, G.L.; Pearsall, A.W.; Grishko, V. Mitochondrial DNA damage is involved in apoptosis caused by pro-inflammatory cytokines in human OA chondrocytes. Osteoarthr. Cartil. 2010, 18, 424-432. [CrossRef] [PubMed]

63. López-Armada, M.J.; Riveiro-Naveira, R.R.; Vaamonde-García, C.; Valcárcel-Ares, M.N. Mitochondrial dysfunction and the inflammatory response. Mitochondrion 2013, 13, 106-118. [CrossRef] [PubMed]

64. Rius-Pérez, S.; Torres-Cuevas, I.; Millán, I.; Ortega, Á.; Pérez, S. PGC-1 $\alpha$, Inflammation, and Oxidative Stress: An Integrative View in Metabolism. Oxid. Med. Cell. Longev. 2020, 2020, 1452696. [CrossRef]

65. Lehman, J.J.; Barger, P.M.; Kovacs, A.; Saffitz, J.E.; Medeiros, D.M.; Kelly, D.P. Peroxisome proliferator-activated receptor gamma coactivator-1 promotes cardiac mitochondrial biogenesis. J. Clin. Investig. 2000, 106, 847-856. [CrossRef] [PubMed]

66. Pereira, R.O.; Wende, A.R.; Crum, A.; Hunter, D.; Olsen, C.D.; Rawlings, T.; Riehle, C.; Ward, W.F.; Abel, E.D. Maintaining PGC-1 $\alpha$ expression following pressure overload-induced cardiac hypertrophy preserves angiogenesis but not contractile or mitochondrial function. FASEB J. 2014, 28, 3691-3702. [CrossRef]

67. Sack, M.N.; Kelly, D.P. The energy substrate switch during development of heart failure: Gene regulatory mechanisms (Review). Int. J. Mol. Med. 1998, 1, 17-24. [CrossRef]

68. Tong, M.; Sadoshima, J. Mitochondrial autophagy in cardiomyopathy. Curr. Opin. Genet. Dev. 2016, 38, 8-15. [CrossRef]

69. Zweier, J.L.; Flaherty, J.T.; Weisfeldt, M.L. Direct measurement of free radical generation following reperfusion of ischemic myocardium. Proc. Natl. Acad. Sci. USA 1987, 84, 1404-1407. [CrossRef]

70. Garlick, P.B.; Davies, M.J.; Hearse, D.J.; Slater, T.F. Direct detection of free radicals in the reperfused rat heart using electron spin resonance spectroscopy. Circ. Res. 1987, 61, 757-760. [CrossRef]

71. Tosaki, A.; Braquet, P. DMPO and reperfusion injury: Arrhythmia, heart function, electron spin resonance, and nuclear magnetic resonance studies in isolated working guinea pig hearts. Am. Heart J. 1990, 120, 819-830. [CrossRef]

72. Zorov, D.B.; Juhaszova, M.; Sollott, S.J. Mitochondrial ROS-induced ROS release: An update and review. Biochim. Biophys. Acta 2006, 1757, 509-517. [CrossRef] [PubMed]

73. Halliwell, B. Lipid peroxidation, antioxidants and cardiovascular disease: How should we move forward? Cardiovasc. Res. 2000, 47, 410-418. [CrossRef]

74. Schrauwen, P.; Schrauwen-Hinderling, V.; Hoeks, J.; Hesselink, M.K. Mitochondrial dysfunction and lipotoxicity. Biochim. Biophys. Acta 2010, 1801, 266-271. [CrossRef] [PubMed]

75. Merkel, M.; Eckel, R.H.; Goldberg, I.J. Lipoprotein lipase: Genetics, lipid uptake, and regulation. J. Lipid Res. 2002, 43, 1997-2006. [CrossRef] [PubMed]

76. Iozzo, P. Myocardial, perivascular, and epicardial fat. Diabetes Care 2011, 34 (Suppl. S2), S371-S379. [CrossRef] [PubMed]

77. Marchington, J.M.; Mattacks, C.A.; Pond, C.M. Adipose tissue in the mammalian heart and pericardium: Structure, foetal development and biochemical properties. Comp. Biochem. Physiol. B 1989, 94, 225-232. [CrossRef]

78. McKinney, M.K.; Cravatt, B.F. Structure and function of fatty acid amide hydrolase. Annu. Rev. Biochem. 2005, 74, 411-432. [CrossRef] [PubMed]

79. Mukhopadhyay, P.; Horváth, B.; Rajesh, M.; Matsumoto, S.; Saito, K.; Bátkai, S.; Patel, V.; Tanchian, G.; Gao, R.Y.; Cravatt, B.F.; et al. Fatty acid amide hydrolase is a key regulator of endocannabinoid-induced myocardial tissue injury. Free Radic. Biol. Med. 2011, 50, 179-195. [CrossRef]

80. Hiley, C.R. Endocannabinoids and the heart. J. Cardiovasc. Pharmacol. 2009, 53, 267-276. [CrossRef] 